\title{
Impact of Preoperative Thrombocytopenia on the Outcome after Coronary Artery Bypass Grafting
}

Wail Nammas, ${ }^{1} \mathrm{MD}, \mathrm{PhD}$, Magnus Dalén, ${ }^{2} \mathrm{MD}, \mathrm{PhD}$, Stefano Rosato, ${ }^{3} \mathrm{MSc}$, Riccardo Gherli, ${ }^{4} \mathrm{MD}$, Daniel Reichart, ${ }^{5}$ MD, Giuseppe Gatti, ${ }^{6} \mathrm{MD}$, Francesco Onorati, ${ }^{7} \mathrm{MD}$, PhD, Giuseppe Faggian, ${ }^{7} \mathrm{MD}$, Marisa De Feo, ${ }^{8} \mathrm{MD}, \mathrm{PhD}$, Ciro Bancone, ${ }^{8} \mathrm{MD}$, PhD, Sidney Chocron, ${ }^{9} \mathrm{MD}$, Sorosh Khodabandeh, ${ }^{2} \mathrm{MD}$, Giuseppe Santarpino, ${ }^{10} \mathrm{MD}, \mathrm{PhD}$, Antonino S. Rubino, ${ }^{11} \mathrm{MD}$, PhD, Daniele Maselli, ${ }^{12} \mathrm{MD}$, Saverio Nardella, ${ }^{12} \mathrm{MD}$, Antonio Salsano, ${ }^{13} \mathrm{MD}$, Tiziano Gherli, ${ }^{14} \mathrm{MD}$, Francesco Nicolini, ${ }^{14} \mathrm{MD}$, PhD, Marco Zanobini, ${ }^{15} \mathrm{MD}$, Matteo Saccocci, ${ }^{15} \mathrm{MD}$, Karl Bounader, ${ }^{16} \mathrm{MD}$, Paola D’Errigo, ${ }^{3} \mathrm{MSc}$, Tuomas Kiviniemi, ${ }^{1} \mathrm{MD}$, PhD, Eeva-Maija Kinnunen, ${ }^{17} \mathrm{MD}, \mathrm{PhD}$, Andrea Perrotti, ${ }^{9} \mathrm{MD}, \mathrm{PhD}$, Juhani Airaksinen, ${ }^{1} \mathrm{MD}, \mathrm{PhD}$, Giovanni Mariscalco, ${ }^{18} \mathrm{MD}, \mathrm{PhD}, \mathrm{PhD}$, Vito G. Ruggieri, ${ }^{19} \mathrm{MD}$, and Fausto Biancari, ${ }^{1,17,20} \mathrm{MD}, \mathrm{PhD}$.

\footnotetext{
${ }^{1}$ Heart Center, Turku University Hospital, University of Turku, Turku, Finland;

${ }^{2}$ Department of Molecular Medicine and Surgery, Department of Cardiac Surgery, Karolinska Institutet, Karolinska University Hospital, Stockholm, Sweden;

${ }^{3}$ National Center of Global Health, Istituto Superiore di Sanità, Rome, Italy;

${ }^{4}$ Department of Cardiovascular Sciences, Cardiac Surgery Unit, S. Camillo-Forlanini Hospital, Rome, Italy;

${ }^{5}$ Hamburg University Heart Center, Hamburg, Germany;

${ }^{6}$ Division of Cardiac Surgery, Ospedali Riuniti, Trieste, Italy;

${ }^{7}$ Division of Cardiovascular Surgery, Verona University Hospital, Verona, Italy;

${ }^{8}$ Division of Cardiac Surgery, Department of Cardiothoracic Sciences, Second University of Naples, Naples, Italy;

${ }^{9}$ Department of Thoracic and Cardio-Vascular Surgery, University Hospital Jean Minjoz, Besançon, France;

${ }^{10}$ Cardiovascular Center, Paracelsus Medical University, Nuremberg, Germany; Città di Lecce Hospital GVM Care\&Research, Lecce, Italy;

${ }^{11}$ Centro Clinico-Diagnostico "G.B. Morgagni”, Centro Cuore, Pedara, Italy;

${ }^{12}$ Department of Cardiac Surgery, St. Anna Hospital, Catanzaro, Italy;

${ }^{13}$ Division of Cardiac Surgery, University of Genoa, Genoa, Italy;

${ }^{14}$ Division of Cardiac Surgery, University of Parma, Parma, Italy;

${ }^{15}$ Department of Cardiac Surgery, Centro Cardiologico - Fondazione Monzino IRCCS, University of Milan;

${ }^{16}$ Division of Cardiothoracic and Vascular Surgery, Pontchaillou University Hospital, Rennes, France;

${ }^{17}$ Department of Surgery, Oulu University Hospital and University of Oulu, Oulu, Finland;

${ }^{18}$ Department of Cardiovascular Sciences, Clinical Sciences Wing, University of Leicester, Glenfield Hospital, Leicester, UK;

${ }^{19}$ Division of Cardiothoracic and Vascular Surgery, Robert Debré University Hospital, Reims, France;

${ }^{20}$ Department of Surgery, University of Turku, Turku, Finland.
}

\section{Corresponding Author:}

Prof. Fausto Biancari,

Heart Center, Turku University Hospital, PO Box 52, 20521 Turku, Finland

E-mail: faustobiancari@yahoo.it

Clinical trial number: clinicaltrials.gov Identifier: NCT02319083

Running head: Thrombocytopenia in coronary surgery

Abstract word count: 331 words

Text word count: 2752 words

Keywords: Thrombocytopenia; Platelets; Bleeding, Coronary artery bypass grafting; Cardiac surgery; Surgery.

Funding statement: This study was not financially supported.

Declaration of interest: The authors report no declarations of interest 


\section{Abstract}

The impact of thrombocytopenia on postoperative bleeding and other major adverse events after cardiac surgery is unclear. This issue was investigated in a series of patients who underwent isolated coronary artery bypass grafting (CABG) from the prospective, multicenter E-CABG registry. Preoperative thrombocytopenia was defined as preoperative platelet count $<150 \times 10^{9} / \mathrm{L}$ and it was considered moderate-severe when preoperative platelet count was $<100 \times 10^{9} / \mathrm{L}$. Multilevel mixed-effects regression analysis was performed to adjust the effect of thrombocytopenia on outcomes for baseline and operative covariates as well as for inter-institutional differences in patient-blood management. Among 7189 patients included in this analysis, 599 (8.3\%) had preoperative thrombocytopenia. Patient with preoperative thrombocytopenia had an increased chest drainage output at 12 hours (mean, 519 vs. $456 \mathrm{~mL}$, adjusted coeff. 39, 95\%Cl 18-60) and rates of severe-massive bleeding (UDPB bleeding severity grades 3-4: $12.7 \%$ vs. 8.1\%, adjusted OR 1.47, 95\% Cl 1.11-1.93; E-CABG bleeding severity grades 2-3: $10.4 \%$ vs. $6.1 \%$, adjusted OR $1.78,95 \% \mathrm{Cl} 1.30-2.43)$. Thrombocytopenia was associated with an increased risk of hospital/30-day death (3.2\% vs. $1.9 \%$, adjusted OR 2.02, 95\% Cl 1.20-3.42), 1-year death (5.7\% vs. 3.4\%, adjusted HR 1.68, 95\% Cl 1.16-2.44), deep sternal wound infection (3.5\% vs. $2.4 \%$, adjusted OR 1.65, $95 \% \mathrm{Cl} 1.02$ $2.66)$, acute kidney injury ( $28.1 \%$ vs. $22.2 \%$, OR $1.45,1.18-1.78)$ and prolonged stay in the intensive care unit (mean, 3.6 vs 2.8 days, adjusted coeff. $0.74,95 \% \mathrm{Cl} 0.40-1.09$ ). Similar results were observed in a subset of patients with moderate-severe thrombocytopenia (51 patients, $0.7 \%$ ). In particular, these patients had a markedly higher rate of acute kidney injury (40\%, adjusted OR, 1.94, 95\% Cl 1.05-3.57), resternotomy for bleeding (7.8\%, adjusted OR 3.49, 95\% Cl 1.20-10.21), and severe-massive bleeding (UDPB bleeding severity grades 3-4: 23.5\%, adjusted OR 3.08, 95\% Cl 1.52-6.22; E-CABG bleeding severity grades 2-3: $23.5 \%$, adjusted $\mathrm{OR} 4.43,95 \% \mathrm{Cl}$ 2.15-9.15) compared to patients with normal preoperative platelet count. Mild preoperative thrombocytopenia is associated with increased risk of severe-massive bleeding, mortality and other major adverse events after CABG. Such risks are markedly increased in patients with moderate-severe preoperative thrombocytopenia.

\section{Introduction}

Major bleeding is a common complication after cardiac surgery. It is associated with an increased use of blood products, stroke, acute kidney injury, perioperative myocardial infarction, with consequent increase in mortality and excessive use of resources [1,2]. Impaired platelet function, mostly due to preoperative use of potent antiplatelet medications, is a well-recognized cause of major bleeding following cardiac surgery $[3,4]$. Randomized trial data suggested that point-of-care platelet function testing in an integrated transfusion algorithm reduces postoperative major bleeding and blood product transfusion [5]. Yet, a meta-analysis of randomized trials demonstrated that point-of-care platelet function testing to guide blood product transfusion did not improve the main clinical endpoints, although it reduced red blood cell and platelet transfusions [6]. Little is known about the impact of preoperative platelet count on postoperative major bleeding after cardiac surgery. We sought to explore the effect of preoperative thrombocytopenia on the incidence of postoperative major bleeding and other adverse events in patients who underwent isolated coronary artery bypass grafting (CABG) from the multicenter E-CABG registry.

\section{Methods}




\section{Study Cohort}

E-CABG registry is a prospective, multicenter study that enrolled patients undergoing isolated CABG at 16 European centers of cardiac surgery from Finland, France, Italy, Germany, Sweden and United Kingdom. The detailed protocol and definition criteria were published before [7]. Data were collected prospectively and underwent robust validation and checking of its quality. Data submissions were constantly verified with regular data quality reports, with review of administrative and medical chart audits in order to correct clinical and temporal conflicts and/or discrepancies. The study was approved by the Institutional Review Board of the participating centers, and it was not supported financially. Informed consent was obtained in institutions where it was specifically required by the internal Institutional Review Board, otherwise it was waived. The study is registered in clinicaltrials.gov (Identifier: NCT02319083).

\section{Definitions and endpoints}

Preoperative thrombocytopenia was defined as preoperative platelet count $<150 \times 10^{9} / \mathrm{L}$ as measured the day before surgery or on the day of surgery. Thrombocytopenia was considered moderate-severe when preoperative platelet count was $<100 \times 10^{9} /$ L. All the end-points of this registry were pre-specified [7]. The primary outcomes were reoperation for bleeding, use of blood products, as well as the severe-massive bleeding as graded by the ECABG [7] and Universal Definition of Perioperative Bleeding (UDPB) bleeding severity stratification methods [1]. Secondary endpoints included hospital/30-day mortality, 1-year mortality, stroke, prolonged inotropic support, need of intra-aortic balloon pump and/or extra-corporeal membrane oxygenation, deep sternal wound infection, atrial fibrillation, acute kidney injury, de novo dialysis, chest drainage output at 12 hours after surgery, nadir levels of hemoglobin and hematocrit, and length of stay in the intensive care unit. In this study, the length of hospital stay was not considered as an endpoint since the timing of patient discharge could have been influenced by the resources of postoperative rehabilitation.

Regarding the definition criteria of the end-points, reoperation for bleeding was considered any resternotomy for excessive bleeding performed during the index hospitalization. Use of blood products was defined as any transfusion of red blood cells, fresh frozen plasma and/or platelets as well as administration of fibrinogen, prothrombin complex concentrate, cryoprecipitate and recombinant factor VIla intraoperatively and/or during the index hospitalization. Nadir levels of hemoglobin and hematocrit were the lowest levels of these parameters measured on the day of surgery. According to the E-CABG bleeding classification, severe-massive bleeding was defined as any reoperation for excessive bleeding and/or transfusion $>4$ units of red blood cells. According to the UDPB bleeding classification, severe-massive bleeding was defined as chest tube blood loss within 12 hours $>1000 \mathrm{~mL}$ and/or reoperation for excessive bleeding and/or transfusion $>4$ units of red blood cells and/or transfusion $>4$ units of fresh frozen plasma after closure of the chest. Hospital/30-day mortality was defined as all-cause death occurring during the index hospitalization or within 30 days after CABG. One-year mortality was defined as all-cause death occurring within one year after CABG. Stroke was defined as any focal or global neurological syndrome occurring during the index hospitalization caused by ischemia and/or hemorrhage not resolving within $24 \mathrm{~h}$. The diagnosis and nature of stroke was made on the basis of findings at computed tomography and/or magnetic resonance imaging of the brain and confirmed by a neurologist. Prolonged inotropic support refers to the use of use of epinephrine, norepinephrine, milrinone, amrinone, dobutamine, 
dopamine, levophed and/or levosimedan for $>12 \mathrm{~h}$ after surgery. Need of intra-aortic balloon pump and/or extra-corporeal membrane oxygenation refers to the use of these mechanical circulatory supports method after surgery and anytime during the index hospitalization. Deep sternal wound and mediastinitis were defined as a surgical site infection occurring within 3 months after surgery involving deep soft tissues, sternum and/or mediastinum with purulent drainage or abscess, with or without fever $\left(>38^{\circ} \mathrm{C}\right)$, detected at direct examination, during reoperation, or radiologic examination and requiring antibiotic treatment with or without reoperation. Postoperative atrial fibrillation was defined as any new event of atrial fibrillation occurred after CABG and detected at electrocardiogram, requiring or not pharmacological/electrical cardioversion. Acute kidney injury was defined as an increase in serum creatinine $\geq 1.5$ times the baseline level or serum creatinine increase $\geq 26.5$ $\mu \mathrm{mol} / \mathrm{I}$ within seven days after surgery and/or de novo renal replacement therapy. The length of stay in the intensive care unit was defined as the number of days the patient was treated in the intensive care unit after surgery considering also readmissions during the same index hospitalization.

\section{Statistical Analysis}

Statistical analysis was performed using a SPSS v. 24.0 (IBM Corporation, New York, USA) and Stata v. 14.2 (StataCorp LLC, Texas, USA). Covariates and outcomes were reported as counts and percentages, and as mean and standard deviation. The Mann-Whitney, Kruskal-Wallis, Chi-square and Fisher Exact tests were used to compare baseline and operative covariates between the study cohorts. In view of the significant baseline differences between patients with and those without preoperative thrombocytopenia as well as interinstitutional differences in surgical techniques, perioperative care, perioperative bleeding and patient-blood management strategies, all outcomes were adjusted in multilevel mixed-effects logistic, linear and Cox proportional hazard regression models for the following covariates: age, gender, baseline hemoglobin, estimated glomerular filtration rate, $\mathrm{P}_{2} \mathrm{Y}_{12}$ inhibitors administered within 5 days from surgery, aspirin administered within 7 days from surgery, oral anticoagulants administered within 3 days from surgery, diabetes, stroke or transient ischemic attack, atrial fibrillation, pulmonary disease, extracardiac arteriopathy, urgent procedure, left ventricular ejection fraction $\leq 50 \%$, critical preoperative state, prior cardiac surgery, prior percutaneous coronary intervention, off-pump surgery, bilateral internal mammary artery grafting and number of distal anastomoses. We did not include the duration of cross-clamping and cardiopulmonary bypass, because a significant number of patients in this series underwent off-pump CABG. The Kaplan-Meier method with the log-rank test was used to evaluate the differences in mid-term survival in the study cohorts. Since moderate-severe thrombocytopenia (platelet count $<100 \times 10^{9} / \mathrm{L}$ ) was present in a limited number of patients, but still might have had an impact on the study outcomes, further analyses were performed in three study cohorts with the following preoperative platelet counts: $<100 \times 10^{9} / \mathrm{L}, 100-149 \times 10^{9} / \mathrm{L}$ and $\geq 150 \times 10^{9} / \mathrm{L}$. All tests were 2 -sided and $\mathrm{p}<0.05$ was set for statistical significance.

\section{Results}

Baseline data

Of the 7352 patients enrolled in the registry, 7189 (97.8\%) with data on preoperative platelet count were included in the final analysis. Mean age of the cohort was $67.3 \pm 9.4$ years; $16.1 \%$ were females; $31.0 \%$ diabetics; 
45.8\% underwent urgent procedure; 20.4\% underwent off-pump surgery. Mean preoperative EuroSCORE II was $2.8 \pm 4.1 \%$. Of the enrolled cohort, 599 patients (8.3\%) had a platelet count $<150 \times 10^{9} / \mathrm{L}, 51$ patients $(0.7 \%)$ had a platelet count $<100 \times 10^{9} / \mathrm{L}$ and 18 patients $(0.3 \%)$ had a platelet count $<75 \times 10^{9} / \mathrm{L}$. In patients with preoperative thrombocytopenia, mean platelet count was $127.5 \pm 19.7 \times 10^{9} / \mathrm{L}$ (median, $133 \times 10^{9} / \mathrm{L}$; range, $30 \mathrm{x}$ $\left.10^{9} / \mathrm{L}-149 \times 10^{9} / \mathrm{L}\right)$. Baseline characteristics and operative data of these cohorts are summarized in Table 1.

The prevalence of preoperative platelet count $<150 \times 10^{9} / \mathrm{L}$ significantly varied between participating centers ranging from $4.5 \%$ to $15.5 \%$ ( $p<0.0001)$. Multilevel mixed-effects logistic regression showed that advanced age (per year, OR 1.02, 95\% $\mathrm{Cl} 1.01-1.03$ ) and low hemoglobin level (per unit, OR 0.99, 0.98-0.99) were predictive of preoperative platelets level $<150 \times 10^{9} / \mathrm{L}$, whereas female gender (OR $\left.0.43,95 \% \mathrm{Cl} 0.31-0.56\right)$ and pulmonary disease (OR $0.72,95 \% \mathrm{Cl} 0.52-0.98$ ) were associated with a significantly lower risk of thrombocytopenia.

\section{Impact of preoperative thrombocytopenia on postoperative outcome}

The mean hospital stay was $9.9 \pm 7.3$ days and the mean length of follow-up $1.2 \pm 0.7$ years. The amount of chest drainage output at 12 hours (range, mean $288 \pm 90 \mathrm{~mL}$ to $749 \pm 501, \mathrm{p}<0.0001$ ) as well as the rates of resternotomy for bleeding (range, 0-6.8\%, $\mathrm{p}<0.0001$ ), E-CABG bleeding grades 2-3 (range, 0.4-17.5\%, $\mathrm{p}<0.0001$ ) and UDPB bleeding grades $3-4$ (range, $0-22.2 \%, p<0.0001$ ) significantly varied between centers. Such differences justified a multilevel mixed-effect regression approach to adjust the risk estimates of adverse events for hospital-level confounders.

Multivariate analysis showed that off-pump surgery did not decreased the risk of severe-massive bleeding (ECABG bleeding grades 2-3: OR 1.13, 95\% Cl 0.47-2.76; UDPB bleeding grades 3-4: OR 1.14, 95\% Cl 0.52-2.51) compared to on-pump surgery.

Multivariate analysis showed that preoperative platelet count as continuous variable was not predictive of resternotomy for bleeding $(p=0.163)$, UDPB bleeding grades $3-4(p=0.165)$ and $E-C A B G$ bleeding grades 2-3 $(p=0.230)$. However, higher preoperative platelet count was associated with reduced amount of chest output at 12 hours $(p<0.0001)$, need of transfusion of platelets $(p<0.0001)$ and fresh frozen plasma $(p=0.030)$ as well as administration of fibrinogen $(p=0.005)$. Furthermore, higher platelet count was associated with a trend toward decreased amount of red blood cells units transfusion both intraoperatively $(p=0.056)$ and postoperatively $(p=0.098)$.

Patient with platelet count $<150 \times 10^{9} / \mathrm{L}$ had increased chest drainage output at 12 hours postoperatively (mean, 519 vs. $456 \mathrm{~mL}$, adjusted coeff. 39, 95\% Cl 18-60) and an increased risk of major-massive bleeding (UDPB bleeding severity grades $3-4: 12.7 \%$ vs. $8.1 \%$, adjusted OR 1.47, 95\% Cl 1.11-1.93; E-CABG bleeding severity grades 2-3: $10.4 \%$ vs. $6.1 \%$, adjusted OR $1.78,95 \% \mathrm{Cl} 1.30-2.43$ ) (Tab. 2). Patients with thrombocytopenia had a significantly increased risk of hospital/30-day death (3.2\% vs. $1.9 \%$, adjusted OR 2.02, 95\%Cl 1.20-3.42), 1-year death $(5.7 \%$ vs. $3.4 \%$, adjusted $\mathrm{HR} 1.68,95 \% \mathrm{Cl} 1.16-2.44)$, deep sternal wound infection (3.5\% vs. 2.4\%, adjusted OR 1.65 , $95 \% \mathrm{Cl} 1.02-2.66)$, acute kidney injury (28.1\% vs. $22.2 \%$, OR $1.45,1.18-1.78)$ and prolonged length of stay in the intensive care unit (mean, 3.6 vs 2.8 days, adjusted coeff. $0.74,95 \% \mathrm{Cl} 0.40-1.09$ ).

Similar results were observed in a subset of patients with preoperative platelet count $<100 \times 10^{9} / \mathrm{L}$ (51 patients, $0.7 \%$ ) (Tab. 3). In particular, patients with moderate-severe thrombocytopenia had a significantly higher rate of acute kidney injury (40\%, adjusted OR, $1.94,95 \% \mathrm{Cl} 1.05-3.57)$, resternotomy for bleeding (7.8\%, adjusted OR 
$3.49,95 \% \mathrm{Cl}$ 1.20-10.21), and had higher rate of severe-massive bleeding (UDPB bleeding severity grades 3-4: 23.5\%, adjusted OR 3.08, 95\% Cl 1.52-6.22; E-CABG bleeding severity grades 2-3: $23.5 \%$, adjusted OR $4.43,95 \% \mathrm{Cl}$ 2.15-9.15) compared to patients with normal preoperative platelet count.

\section{Discussion}

In the current analysis of the multicentre E-CABG registry data, preoperative thrombocytopenia was not uncommon in patients undergoing contemporary isolated CABG and it was associated with increased early postoperative blood loss, severe-massive bleeding and other major adverse events. Such risks seem increased particularly in patients with preoperative platelet count $<100 \times 10^{9} / \mathrm{L}$. Indeed, one fourth of them experienced severe-massive bleeding as defined by the E-CABG and UDPB bleeding severity stratification criteria. It is worth noting that the impact of thrombocytopenia on these outcomes was adjusted for baseline and operative covariates as well as preoperative use of antithrombotics and any possible interinstitutional differences in patient-blood management using multilevel mixed-effects regression methods.

Investigation of factors associated with bleeding after CABG is crucial for reduction of the bleeding events and improvement of the outcome after cardiac surgery. Many preoperative factors such as prior bleeding history, preoperative hemoglobin, platelet dysfunction, time of discontinuation of antiplatelet medications before surgery are independently associated with perioperative bleeding and allogenic blood product transfusion [8]. Thrombocytopenia may intuitively be associated with increased perioperative bleeding. In a single-centre observational study, lower preoperative platelet count was independently associated with excessive bleeding after cardiac surgery [9]. However, the mean value of platelet count in patients who experienced excessive bleeding was within the normal range; the cutoff value of platelet count associated with postoperative bleeding risk was $214 \times 10^{9} / \mathrm{L}$ [9]. Other abnormalities of the coagulation system might have probably contributed to episodes of excessive bleeding in that study. In another study by the same investigators, lower preoperative platelet count was associated with re-exploration for bleeding in univariate, but not in multivariate analysis [10]. In a previous observational study of children undergoing cardiac surgery, lower platelet count during cardiopulmonary bypass was the variable most significantly associated with intraoperative and 12-hour blood loss in linear regression analysis (cutoff value was platelet count of $108 \times 10^{9} / \mathrm{L}$ ) [11]. Other observational studies showed that lower post-bypass platelet count independently predicted early postoperative blood loss [12-14]. These findings are of clinical importance in view of the expected reduction of platelet count after cardiopulmonary bypass [15].

Similarly, in registry data of patients with atrial fibrillation who underwent percutaneous coronary intervention, preprocedural thrombocytopenia $\left(<150 \times 10^{9} / \mathrm{L}\right)$ was not associated with postprocedural bleeding, thromboembolic event rates and mortality [16]. Remarkably, in that registry study, prescribed antithrombotic medications were comparable between the two groups. Yet, in another registry data analysis, preprocedural thrombocytopenia before percutaneous coronary intervention was associated with more in-hospital major bleeding events, and independently predicted in-hospital mortality after urgent procedures [17].

Preoperative thrombocytopenia is recognized as a risk factor for bleeding and other adverse outcomes after noncardiac surgery [18]. The evidence of an increased risk of perioperative bleeding after cardiac surgery associated preoperative thrombocytopenia is derived from a few studies [19-22]. A recent study by Ranucci and collegues 
[19] demonstrated that preoperative platelet count and P2Y12-dependent platelet function were linearly associated along the whole spectrum of platelet count, and both were independent predictors of postoperative bleeding in multivariable analysis.

In the present study, a preoperative platelet count $<150 \times 10^{9} / \mathrm{L}$ as adjusted for baseline and operative covariates by propensity score matching was associated with greater chest drainage output at 12-hour as well as higher risk of severe-massive bleeding as defined by the E-CABG [7] and UDPB [1] bleeding severity criteria. Furthermore, patients with thrombocytopenia received similar amounts of red blood cell units after surgery. When only patients with a preoperative platelet count $<100 \times 10^{9} / \mathrm{L}$ were compared, despite its low prevalence, it was invariably associated with an increased risk of blood loss, use of blood products and reoperation for bleeding. Importantly, one fourth of these patients experience severe-massive bleeding defined according to the E-CABG and UDPB bleeding severity classifications.

Recent studies from the Duke University Medical Center showed that postoperative thrombocytopenia were associated with increased risk of stroke, acute kidney injury and mortality after CABG [21,22]. The present study confirms some of these prior findings as thrombocytopenia was associated with an increased risk of early and 1year mortality, deep wound infection, acute kidney injury and atrial fibrillation along with longer stay in the intensive care unit. The direct role of decreased platelet count on these major adverse events is unclear. However, since perioperative thrombocytopenia was associated with significantly greater exposure to blood products and likely to increased blood loss and anemia [21,22], we speculate that thrombocytopenia may exert its negative effects through an increased risk of perioperative bleeding and exposure to blood products and prothrombotic agents. Other studies are needed to confirms these findings and investigate any direct effect of thrombocytopenia on postoperative end-organ injury.

\section{Limitations}

The current study has some limitations including unmeasured confounders and selection bias, which might have influenced the results. First, platelet dysfunction, fibrinogen level, thrombin generation, excessive fibrinolysis, and the viscoelastic properties of whole blood might have influenced major bleeding events in our cohort. Second, this registry did not collect data on preoperative use of blood products, therefore it is unclear whether some of these patients had their thrombocytopenia corrected before surgery. Third, the lack of intra- and postoperative levels of platelets prevented an analysis of the impact of perioperative thrombocytopenia on bleeding and other adverse events. Furthermore, lack of standardization of surgical strategy, perioperative care and intravenous fluid therapy and transfusion protocol might be sources of bias of this analysis. However, these potential biases were addressed in multilevel mixed-effects regression analyses.

\section{Conclusions}

The results of this large multicentre study showed that preoperative thrombocytopenia is associated with increased risk of severe-massive perioperative bleeding, mortality and other major adverse events after CABG. Such risks are markedly increased in patients with moderate-severe preoperative thrombocytopenia.

\section{References}


[1] Dyke C, Aronson S, Dietrich W, Hofmann A, Karkouti K, Levi M, Murphy GJ, Sellke FW, Shore-Lesserson L, von Heymann C, Ranucci M. Universal definition of perioperative bleeding in adult cardiac surgery. J Thorac Cardiovasc Surg 2014;147:1458-1463.

[2] Ranucci M, Baryshnikova E, Castelvecchio S, Pelissero G; Surgical and Clinical Outcome Research (SCORE) Group. Major bleeding, transfusions, and anemia: the deadly triad of cardiac surgery. Ann Thorac Surg 2013;96:478-85.

[3] Berger JS, Frye CB, Harshaw Q, Edwards FH, Steinhubl SR, Becker RC. Impact of clopidogrel in patients with acute coronary syndromes requiring coronary artery bypass surgery: a multicenter analysis. J Am Coll Cardiol 2008;52:1693-701

[4] Kunadian B, Thornley AR, Tanos M, Dunning J. Should clopidogrel be stopped prior to urgent cardiac surgery? Interact Cardiovasc Thorac Surg 2006;5:630-6.

[5] Karkouti K, Callum J, Wijeysundera DN, Rao V, Crowther M, Grocott HP, Pinto R, Scales DC; TACS Investigators. Point-of-care hemostatic testing in cardiac surgery: a stepped-wedge clustered randomized controlled trial. Circulation 2016;134:1152-1162.

[6] Serraino GF, Murphy GJ. Routine use of viscoelastic blood tests for diagnosis and treatment of coagulopathic bleeding in cardiac surgery: updated systematic review and meta-analysis. Br J Anaesth 2017;118:823-833

[7] Biancari F, Ruggieri VG, Perrotti A, Svenarud P, Dalén M, Onorati F, Faggian G, Santarpino G, Maselli D, Dominici C, Nardella S, Musumeci F, Gherli R, Mariscalco G, Masala N, Rubino AS, Mignosa C, De Feo M, Della Corte A, Bancone C, Chocron S, Gatti G, Gherli T, Kinnunen EM, Juvonen T. European multicenter study on coronary artery bypass grafting (E-CABG registry): study protocol for a prospective clinical registry and proposal of classification of postoperative complications. J Cardiothorac Surg 2015;10:90.

[8] Emeklibas N, Kammerer I, Bach J, Sack FU, Hellstern P. Preoperative hemostasis and its association with bleeding and blood component transfusion requirements in cardiopulmonary bypass surgery. Transfusion 2013;53:1226-34.

[9] Lopes CT, Brunori EF, Cavalcante AM, Moorhead SA, Swanson E, Lopes Jde L, de Barros AL. Factors associated with excessive bleeding after cardiac surgery: A prospective cohort study. Heart Lung 2016;45:64-69.

[10] Lopes CT, Brunori EH, Santos VB, Moorhead SA, Lopes Jde L, de Barros AL. Predictive factors for bleedingrelated re-exploration after cardiac surgery: A prospective cohort study. Eur J Cardiovasc Nurs 2016;15:e70-7.

[11] Williams GD, Bratton SL, Riley EC, Ramamoorthy C. Coagulation tests during cardiopulmonary bypass correlate with blood loss in children undergoing cardiac surgery. J Cardiothorac Vasc Anesth 1999;13:398-404.

[12] Ichikawa J, Osada Y, Kodaka M, Nishiyama K, Komori M. Association between platelet count and postoperative blood loss in patients undergoing cardiac surgery with cardiopulmonary bypass and fresh frozen plasma administration guided by thromboelastometry. Circ J 2018 (in press) DOI: 10.1253/circj.CJ-17-0712

[13] Karkouti K, McCluskey SA, Syed S, Pazaratz C, Poonawala H, Crowther MA. The influence of perioperative coagulation status on postoperative blood loss in complex cardiac surgery: a prospective observational study. Anesth Analg 2010;110:1533-40.

[14] Pillai RC, Fraser JF, Ziegenfuss M, Bhaskar B. Influence of circulating levels of fibrinogen and perioperative coagulation parameters on predicting postoperative blood loss in cardiac surgery: a prospective observational 
study. J Card Surg 2014;29:189-95.

[15] Khuri SF, Wolfe JA, Josa M, Axford TC, Szymanski I, Assousa S, Ragno G, Patel M, Silverman A, Park M. Hematologic changes during and after cardiopulmonary bypass and their relationship to the bleeding time and nonsurgical blood loss. J Thorac Cardiovasc Surg 1992;104:94-107.

[16] Kiviniemi T, Karjalainen P, Rubboli A, Schlitt A, Tuomainen P, Niemelä M, Laine M, Biancari F, Lip GY, Airaksinen KE. Thrombocytopenia in patients with atrial fibrillation on oral anticoagulation undergoing percutaneous coronary intervention. Am J Cardiol 2013;112:493-8.

[17] Overgaard CB, Ivanov J, Seidelin PH, Todorov M, Mackie K, Dzavík V. Thrombocytopenia at baseline is a predictor of inhospital mortality in patients undergoing percutaneous coronary intervention. Am Heart J 2008;156:120-4.

[18] Glance LG, Blumberg N, Eaton MP, Lustik SJ, Osler TM, Wissler R, Zollo R, Karcz M, Feng C, Dick AW. Preoperative thrombocytopenia and postoperative outcomes after noncardiac surgery. Anesthesiology 2014;120:62-75.

[19] Ranucci M, Baryshnikova E. The interaction between preoperative platelet count and function and its relationship with postoperative bleeding in cardiac surgery. Platelets 2017;28:794-798.

[20] Miana LA, Atik FA, Moreira LP, Hueb AC, Jatene FB, Auler JO Jr, de Oliveira SA. Risk factors for postoperative bleeding after adult cardiac surgery. Rev Bras Cir Cardiovasc 2004;19:280-286.

[21] Kertai MD, Zhou S, Karhausen JA, Cooter M, Jooste E, Li YJ, White WD, Aronson S, Podgoreanu MV, Gaca J, Welsby IJ, Levy JH, Stafford-Smith M, Mathew JP, Fontes ML. Platelet counts, acute kidney injury, and mortality after coronary artery bypass grafting surgery. Anesthesiology 2016;124:339-52.

[22] Karhausen JA, Smeltz AM, Akushevich I, Cooter M, Podgoreanu MV, Stafford-Smith M, Martinelli SM, Fontes $\mathrm{ML}$, Kertai MD. Platelet counts and postoperative stroke after coronary artery bypass grafting surgery. Anesth Analg 2017;125:1129-1139.

[23] Kuss O, von Salviati B, Börgermann J. Off-pump versus on-pump coronary artery bypass grafting: a systematic review and meta-analysis of propensity score analyses. J Thorac Cardiovasc Surg 2010;140:829-35.

[24] Deppe AC, Arbash W, Kuhn EW, Slottosch I, Scherner M, Liakopoulos OJ, Choi YH, Wahlers T. Current evidence of coronary artery bypass grafting off-pump versus on-pump: a systematic review with meta-analysis of over 16,900 patients investigated in randomized controlled trial. Eur J Cardiothorac Surg 2016;49:1031-41.

[25] Bednar F, Osmancik P, Vanek T, Mocikova H, Jares M, Straka Z, Widimsky P. Platelet activity and aspirin efficacy after off-pump compared with on-pump coronary artery bypass surgery: results from the prospective randomized trial PRAGUE 11-Coronary Artery Bypass and REactivity of Thrombocytes (CABARET). J Thorac Cardiovasc Surg 2008;136:1054-60. 
Table 1. Baseline characteristics and operative data.

\begin{tabular}{|c|c|c|c|}
\hline & $\begin{array}{c}\text { Platelets count } \\
150-450 \times 10^{9} / \mathrm{L} \\
(\mathrm{N}=6590)\end{array}$ & $\begin{array}{l}\text { Platelets count } \\
<150 \times 10^{9} / \mathrm{L} \\
(\mathrm{N}=599)\end{array}$ & $\mathrm{p}$-value \\
\hline Age (years) & $67.2 \pm 9.4$ & $68.9 \pm 9.2$ & $<0.001$ \\
\hline Female & $1081(16.6)$ & $56(9.4)$ & $<0.001$ \\
\hline Body mass index & $27.6 \pm 4.1$ & $27.6 \pm 4.0$ & 0.95 \\
\hline Hemoglobin (g/L) & $137 \pm 16$ & $134 \pm 19$ & 0.001 \\
\hline eGFR (mL/min/1.73 $\left.\mathrm{m}^{2}\right)$ & $81.5 \pm 25.0$ & $81.8 \pm 29.6$ & 0.82 \\
\hline Dialysis & $68(1.0)$ & $12(2.0)$ & 0.03 \\
\hline Hypertension & $5181(79.5)$ & $481(81.1)$ & 0.36 \\
\hline Diabetes & $2035(31.2)$ & $177(29.8)$ & 0.48 \\
\hline Recent myocardial infarction & $2093(32.1)$ & $179(30.2)$ & 0.32 \\
\hline Prior stroke/transient ischemic attack & $380(5.8)$ & $31(5.2)$ & 0.54 \\
\hline Atrial fibrillation & $520(8)$ & $58(9.8)$ & 0.12 \\
\hline Pulmonary disease & $681(10.5)$ & $48(8.1)$ & 0.06 \\
\hline Extracardiac arteriopathy & $1473(22.6)$ & $139(23.4)$ & 0.64 \\
\hline Ejection fraction $\leq 50 \%$ & $1886(29.0)$ & $170(28.7)$ & 0.87 \\
\hline Prior percutaneous coronary intervention & $1340(20.6)$ & $154(26.0)$ & 0.002 \\
\hline Prior cardiac surgery & $30(0.5)$ & $8(1.3)$ & 0.004 \\
\hline Poor mobility & $168(2.6)$ & $12(2.0)$ & 0.40 \\
\hline Critical preoperative state & $404(6.2)$ & $54(9.1)$ & 0.005 \\
\hline Urgency of surgery & & & 0.445 \\
\hline Elective & $3552(54.5)$ & $307(51.8)$ & \\
\hline Urgent & $2655(40.8)$ & $259(43.7)$ & \\
\hline Emergency & $305(4.7)$ & $27(4.6)$ & \\
\hline Aspirin within 7 days & $5747(88.2)$ & $512(86.3)$ & 0.17 \\
\hline P2Y12 within 5 days & $979(15.1)$ & $72(12.2)$ & 0.06 \\
\hline Oral anticoagulation within 3 days & $51(0.8)$ & $6(1.0)$ & 0.54 \\
\hline WILL-BLEED score & $3.9 \pm 3.6$ & $4.2 \pm 3.7$ & 0.14 \\
\hline EuroSCORE II & $2.8 \pm 4.1$ & $3.0 \pm 3.9$ & 0.16 \\
\hline CathPCl score & $43.5 \pm 21.0$ & $44.0 \pm 19.7$ & 0.55 \\
\hline Number of aortic anastomoses & $0.9 \pm 0.9$ & $1.0 \pm 0.8$ & 0.003 \\
\hline Number of distal anastomoses & $2.7 \pm 0.9$ & $2.7 \pm 0.9$ & 0.99 \\
\hline Cardiopulmonary bypass time (min) & $84.7 \pm 34.7$ & $86.6 \pm 38.8$ & 0.29 \\
\hline Aortic clamping time (min) & $57.1 \pm 25.6$ & $56.6 \pm 26.0$ & 0.67 \\
\hline Off-pump surgery & $1344(20.6)$ & $104(17.5)$ & 0.07 \\
\hline Bilateral internal mammary artery graft & $2399(36.8)$ & $191(32.2)$ & 0.02 \\
\hline
\end{tabular}

Continuous variables are reported as mean and standard deviation. Nominal variables are reported as counts and percentages. Clinical variables are according to the EuroSCORE II definition criteria. eGFR indicates estimated glomerular filtration rate according to the MDRD equation. 
Table 2. Outcomes in the study cohorts.

\begin{tabular}{|c|c|c|c|c|c|}
\hline Outcomes & $\begin{array}{l}\text { Platelets count } \\
150-450 \times 10^{9} / \mathrm{L} \\
(\mathrm{N}=6590)\end{array}$ & $\begin{array}{l}\text { Platelets count } \\
<150 \times 10^{9} / \mathrm{L} \\
(\mathrm{N}=599)\end{array}$ & $\begin{array}{c}\text { Univariate } \\
\text { analysis } \\
\text { p-value }\end{array}$ & $\begin{array}{c}\text { Multivariate } \\
\text { analysis } \\
\text { p-value }\end{array}$ & $\begin{array}{c}\text { Mixed-effects } \\
\text { multivariate analysis } \\
\text { Estimates }\end{array}$ \\
\hline Hospital/30-day mortality & $123(1.9)$ & $19(3.2)$ & 0.028 & 0.009 & $2.02,1.20-3.42$ \\
\hline 1-year mortality (\%) & 3.4 & 5.7 & 0.009 & 0.006 & $1.68,1.16-2.44$ \\
\hline Intensive care unit stay (days) & $2.8 \pm 3.6$ & $3.6 \pm 8.7$ & 0.045 & $<0.0001$ & $0.74,0.40-1.09$ \\
\hline Stroke & $75(1.1)$ & $7(1.2)$ & 0.946 & 0.947 & $1.03,0.46-2.28$ \\
\hline Prolonged inotropic support & $1784(27.1)$ & $214(35.7)$ & $<0.0001$ & 0.115 & $1.20,0.96-1.49$ \\
\hline Intra-aortic balloon pump & $291(4.4)$ & $27(4.5)$ & 0.917 & 0.471 & $0.84,0.52-1.36$ \\
\hline Postoperative ECMO & $42(0.6)$ & $3(0.5)$ & 0.685 & 0.843 & $0.88,0.26-3.03$ \\
\hline Deep sternal wound infection & $157(2.4)$ & $21(3.5)$ & 0.090 & 0.041 & $1.65,1.02-2.66$ \\
\hline KDIGO acute kidney injury & $1442(22.2)$ & $164(28.1)$ & 0.001 & $<0.0001$ & $1.45,1.18-1.78$ \\
\hline De novo dialysis & $112(1.7)$ & $18(3.1)$ & 0.019 & 0.025 & $1.90,1.08-3.17$ \\
\hline Postoperative atrial fibrillation & $1736(26.3)$ & $197(32.9)$ & 0.001 & 0.033 & $1.24,1.02-1.51$ \\
\hline Drainage output at 12 hours (ml) & $456 \pm 300$ & $519 \pm 376$ & $<0.0001$ & $<0.0001$ & $43.01,19.43-66.60$ \\
\hline Nadir hemoglobin $(\mathrm{g} / \mathrm{L})$ & $99 \pm 16$ & $100 \pm 17$ & 0.747 & 0.075 & $0.98,-0.10-2.06$ \\
\hline Nadir hematocrit (\%) & $30.0 \pm 4.8$ & $30.0 \pm 4.8$ & 0.819 & 0.100 & $1.04,-0.13-0.53$ \\
\hline Reoperation for bleeding & $168(2.5)$ & $21(3.5)$ & 0.161 & 0.164 & $1.44,0.88-2.25$ \\
\hline \multicolumn{6}{|l|}{ Blood products } \\
\hline Red blood cells (units) & $1.1 \pm 2.4$ & $1.4 \pm 2.5$ & 0.055 & 0.174 & $0.13,-0.06-0.31$ \\
\hline Fresh frozen plasma & $398(6.0)$ & $57(9.5)$ & 0.001 & 0.010 & $1.52,1.11-2.08$ \\
\hline Platelets & $478(85.1)$ & 89 (14.9) & $<0.0001$ & $<0.0001$ & $3.03,2.27-4.03$ \\
\hline Fibrinogen & $228(3.5)$ & $29(4.8)$ & 0.081 & 0.001 & $2.02,1.33-3.08$ \\
\hline PCC & $108(1.6)$ & $11(1.8)$ & 0.717 & 0.165 & $1.60,0.82-3.10$ \\
\hline Cryoprecipitate & $20(0.3)$ & 0 & 0.405 & 1.000 & - \\
\hline rfVIla & $10(0.2)$ & $1(0.2)$ & 1.000 & 0.932 & $1.10,0.13-9.46$ \\
\hline E-CABG bleeding grades $2-3$ & $404(6.1)$ & $62(10.4)$ & $<0.0001$ & $<0.0001$ & $1.78,1.30-2.43$ \\
\hline UDPB bleeding grades 3-4 & $529(8.1)$ & $75(12.7)$ & $<0.0001$ & 0.007 & $1.47,1.11-1.93$ \\
\hline
\end{tabular}

Continuous variables are reported as mean and standard deviation. Nominal variables are reported as counts and percentages. Estimates are odds ratios or coefficients with 95\%confidence interval. CABG, coronary artery bypass grafting; ECMO, extracorporeal membrane oxygenation; KDIGO, Kidney Disease Improving Global Outcomes; PCC, prothrombin complex concentrate; UDPB, universal definition of perioperative bleeding; rVIla, Recombinant factor VIla. In bold are statistical significant values in multivariate analysis. 
Table 3. Outcomes in cohorts with different preoperative platelet counts.

\begin{tabular}{|c|c|c|c|c|}
\hline & $\begin{array}{c}\text { Platelets count } \\
150-450 \times 10^{9} / \mathrm{L} \\
(\mathrm{N}=6590)\end{array}$ & $\begin{array}{c}\text { Platelets count } \\
100-149 \times 10^{9} / \mathrm{L} \\
\quad(\mathrm{N}=548)\end{array}$ & $\begin{array}{l}\text { Platelets count } \\
<100 \times 10^{9} / \mathrm{L} \\
(\mathrm{N}=51)\end{array}$ & $\begin{array}{c}\text { Mixed-effects } \\
\text { multivariate } \\
\text { analysis } \\
\text { p-value }\end{array}$ \\
\hline Hospital/30-day mortality & $123(1.9)$ & $17(3.1)$ & $2(3.9)$ & 0.009 \\
\hline 1-year mortality (\%) & 3.4 & 5.7 & 4.3 & 0.021 \\
\hline Intensive care unit stay (days) & $2.8 \pm 3.6$ & $3.5 \pm 9.0$ & $4.2 \pm 4.3$ & $<0.0001$ \\
\hline Stroke & $75(1.1)$ & $6(1.1)$ & $1(2.0)$ & 0.803 \\
\hline Prolonged inotropic support & $1784(27.1)$ & $196(35.8)$ & $18(35.3)$ & 0.112 \\
\hline Intra-aortic balloon pump & $291(4.4)$ & $23(4.2)$ & $4(7.8)$ & 0.772 \\
\hline Postoperative ECMO & $42(0.6)$ & $3(0.5)$ & 0 & 0.745 \\
\hline Deep sternal wound infection & $157(2.4)$ & $19(3.5)$ & $2(3.9)$ & 0.046 \\
\hline KDIGO acute kidney injury* & $1442(22.2)$ & $144(27.0)$ & $20(40.0)$ & $<0.0001$ \\
\hline De novo dialysis & $112(1.7)$ & $16(3.0)$ & $2(4.0)$ & 0.021 \\
\hline Postoperative atrial fibrillation & $1736(26.3)$ & $178(32.5)$ & $19(37.3)$ & 0.034 \\
\hline Chest drainage output at $12 \mathrm{~h}(\mathrm{ml})$ & $456 \pm 300$ & $517 \pm 379$ & $535 \pm 356$ & $<0.0001$ \\
\hline Nadir hemoglobin $(\mathrm{g} / \mathrm{mL})$ & $99 \pm 16$ & $100 \pm 17$ & $93 \pm 13$ & 0.152 \\
\hline Nadir hematocrit (\%) & $30 \pm 4.8$ & $30 \pm 5$ & $28 \pm 4$ & 0.312 \\
\hline Resternotomy for bleeding & $168(2.5)$ & $17(3.1)$ & $4(7.8)$ & 0.060 \\
\hline \multicolumn{5}{|l|}{ Blood products } \\
\hline Red blood cells (units) & $1.1 \pm 2.4$ & $1.2 \pm 2.2$ & $2.7 \pm 4.4$ & 0.027 \\
\hline Fresh frozen plasma & $398(6.0)$ & $45(8.2)$ & $12(23.5)$ & 0.001 \\
\hline Platelets & $478(7.3)$ & $69(12.6)$ & $20(39.2)$ & $<0.0001$ \\
\hline Fibrinogen & $228(3.5)$ & $24(4.4)$ & $5(9.8)$ & $<0.0001$ \\
\hline Prothrombin & $108(1.6)$ & $8(1.5)$ & $3(5.9)$ & 0.036 \\
\hline Cryoprecipitate & $20(0.3)$ & 0 & 0 & 1.000 \\
\hline rfVIla & $10(0.2)$ & $1(0.2)$ & 0 & 0.983 \\
\hline E-CABG bleeding grade $2-3$ & $412(6.3)$ & $50(9.1)$ & $12(23.5)$ & $<0.0001$ \\
\hline UDPB bleeding grade $3-4$ & $537(8.2)$ & $63(11.7)$ & $12(23.5)$ & 0.001 \\
\hline
\end{tabular}

Continuous variables are reported as median and interquartile range. Nominal variables are reported as counts and percentages. ${ }^{*}$, patients with CKD class 5 were excluded from the analysis. CABG, coronary artery bypass grafting; ECMO, extracorporeal membrane oxygenation; KDIGO, Kidney Disease Improving Global Outcomes; UDPB, universal definition of perioperative bleeding; rVIla, Recombinant factor VIla. In bold are statistical significant values. 
Table 4. Outcomes in patients operated on with or without cardiopulmonary bypass.

\begin{tabular}{|c|c|c|c|c|c|c|}
\hline \multirow[b]{2}{*}{ Outcomes } & \multicolumn{2}{|c|}{ On-pump CABG } & \multirow[b]{2}{*}{$\begin{array}{l}\text { Mixed-effects } \\
\text { multivariate } \\
\text { analysis } \\
\text { Estimates }\end{array}$} & \multicolumn{2}{|c|}{ Off-pump CABG } & \multirow[b]{2}{*}{$\begin{array}{c}\text { Mixed-effects } \\
\text { multivariate analysis } \\
\text { Estimates }\end{array}$} \\
\hline & $\begin{array}{l}\text { Platelets count } \\
150-450 \times 10^{9} / \mathrm{L} \\
\quad(\mathrm{N}=5231)\end{array}$ & $\begin{array}{c}\text { Platelets } \\
\text { count } \\
<150 \times 10^{9} / \mathrm{L} \\
(\mathrm{N}=494)\end{array}$ & & $\begin{array}{l}\text { Platelets count } \\
150-450 \times 10^{9} / \mathrm{L} \\
\quad(\mathrm{N}=1359)\end{array}$ & $\begin{array}{l}\text { Platelets count } \\
<150 \times 10^{9} / \mathrm{L} \\
(\mathrm{N}=105)\end{array}$ & \\
\hline Hospital/30-day mortality & $97(1.9)$ & $19(3.8)$ & $2.55,1.48-4.38$ & $26(1.9)$ & 0 & $1.00,-$ \\
\hline 1-year mortality (\%) & 3.2 & 6.6 & $1.02,1.23-2.70$ & 4.1 & 1.2 & $1.02,0.99-1.06$ \\
\hline Intensive care unit stay (days) & $2.8 \pm 3.5$ & $3.9 \pm 9.5$ & $0.98,0.59-1.38$ & $2.8 \pm 3.7$ & $2.3 \pm 1.8$ & $-0.38,-1.06-0.30$ \\
\hline Stroke & $67(1.3)$ & $7(1.4)$ & $1.19,0.94-1.52$ & $8(0.6)$ & 0 & $1.22,0.69-1.03$ \\
\hline Prolonged inotropic support & $1517(29.0)$ & $192(38.9)$ & $1.19,0.94-1.52$ & $267(19.6)$ & $22(21.0)$ & $1.22,0.69-2.15$ \\
\hline Intra-aortic balloon pump & $257(4.9)$ & $27(5.5)$ & $0.93,0.57-1.53$ & $34(2.5)$ & 0 & 1.00 \\
\hline Postoperative ECMO & $34(0.6)$ & $3(0.6)$ & $1.14,0.32-4.08$ & $8(0.6)$ & 0 & $1.00,-$ \\
\hline Deep sternal wound infection & $124(2.4)$ & $17(3.4)$ & $1.54,0.90-2.62$ & $33(2.4)$ & $4(3.8)$ & $1.93,0.64-5.82$ \\
\hline KDIGO acute kidney injury & $1112(21.6)$ & $133(27.6)$ & $1.47,1.17-1.84$ & $330(24.8)$ & $31(30.4)$ & $1.37,0.84-2.24$ \\
\hline De novo dialysis & $80(1.5)$ & $15(3.1)$ & $2.17,1.20-3.90$ & $32(2.4)$ & $3(2.9)$ & $0.80,0.16-3.95$ \\
\hline Postoperative atrial fibrillation & $1389(26.6)$ & $163(33.0)$ & $1.24,1.00-1.55$ & $347(25.5)$ & $34(32.4)$ & $1.22,0.74-2.02$ \\
\hline $\begin{array}{l}\text { Drainage output at } 12 \text { hours } \\
\text { (ml) }\end{array}$ & $458 \pm 297$ & $524 \pm 392$ & $\begin{array}{c}47.33,21.48- \\
73.17\end{array}$ & $451 \pm 315$ & $488 \pm 284$ & $18.48,-39.54-76.51$ \\
\hline Nadir hemoglobin $(\mathrm{g} / \mathrm{L})$ & $99 \pm 16$ & $99 \pm 17$ & $0.93,-0.25-2.10$ & $100 \pm 16$ & $101 \pm 16$ & $0.61,-2.07-3.29$ \\
\hline Nadir hematocrit (\%) & $29.9 \pm 4.8$ & $29.8 \pm 4.9$ & $0.17,-0.19-0.57$ & $30.4 \pm 4.7$ & $30.7 \pm 4.3$ & $0.19,-0.67-1.04$ \\
\hline Reoperation for bleeding & $131(2.5)$ & $17(3.4)$ & $1.38,0.81-2.35$ & $37(2.7)$ & $4(3.8)$ & $1.34,0.45-3.97$ \\
\hline \multicolumn{7}{|l|}{ Blood products } \\
\hline Red blood cells (units) & $1.2 \pm 2.3$ & $1.4 \pm 2.6$ & $0.19,-0.01-0.39$ & $0.9 \pm 2.5$ & $0.9 \pm 2.0$ & $-0.17,-0.63-0.28$ \\
\hline Fresh frozen plasma & $326(6.2)$ & $49(9.9)$ & $1.47,1.05-2.08$ & $72(5.3)$ & $8(7.6)$ & $1.53,0.67-3.50$ \\
\hline Platelets & $383(7.3)$ & $72(14.6)$ & $2.76,2.01-3.80$ & $95(7.0)$ & $17(16.2)$ & $4.26,2.12-8.55$ \\
\hline Fibrinogen & $193(3.7)$ & $20(4.0)$ & $1.61,0.98-2.64$ & $35(2.6)$ & $9(8.7)$ & $5.24,2.25-12.21$ \\
\hline PCC & $78(1.5)$ & $7(1.4)$ & $1.39,0.61-3.17$ & $30(2.2)$ & $4(3.8)$ & $2.04,0.63-6.61$ \\
\hline Cryoprecipitate & $16(0.3)$ & 0 & 1.00 & $4(0.3)$ & 0 & 1.00 \\
\hline rfVIla & $7(0.1)$ & 0 & $1.00,-$ & $3(0.2)$ & $1(1.0)$ & $23.20,0.68-792.05$ \\
\hline E-CABG bleeding grades $2-3$ & $328(6.3)$ & $53(10.8)$ & $1.86,1.32-2.61$ & $76(5.6)$ & $9(8.6)$ & $1.34,0.60-3.00$ \\
\hline UDPB bleeding grades 3-4 & $420(8.1)$ & $65(13.3)$ & $1.54,1.14-2.08$ & $109(8.1)$ & $10(9.8)$ & $1.11,0.53-2.34$ \\
\hline
\end{tabular}

Continuous variables are reported as mean and standard deviation. Nominal variables are reported as counts and percentages. Estimates are odds ratios or coefficients with $95 \%$ confidence interval. CABG, coronary artery bypass grafting; ECMO, extracorporeal membrane oxygenation; KDIGO, Kidney Disease Improving Global Outcomes; PCC, prothrombin complex concentrate; UDPB, universal definition of perioperative bleeding; rVIla, Recombinant factor VIla. In bold are statistical significant values in multivariate analysis. 